\section{Significance of Flower Bud Density for Cultivar Evaluation in Almond}

\author{
Ossama Kodad and Rafel Socias i Company ${ }^{1}$ \\ Unidad de Fruticultura, CITA de Aragón, Apartado 727, \\ 50080 Zaragoza, Spain \\ Additional index words. Prunus amygdalus, spur density, alternance, repeatability
}

\begin{abstract}
Flower bud density, spur density, and number of flower buds per spur were evaluated in 57 almond cultivars and selections during 3 consecutive years to establish their repeatability as well as their potential to ensure a sustainable commercial production. These three traits showed a high variability with significant differences between genotypes and years as well as a significant interaction of genotype and year. The effect of location and the interaction of location and genotype were not significant for bud density, but they were for spur density and number of flower buds per spur. Variability of flower bud density is mostly related to the number of flower buds per spur as indicated by the higher repeatability of spur density than that of the other two traits. A high flower bud density is essential for a sustainable production, because a high number of flowers may compensate frost damage. Early selection for a high flower bud density can be done indirectly through selection for a high spur density but requires its evaluation over several years.
\end{abstract}

The initial number of flowers differentiated during the previous season is the first component of yield in fruit trees (Werner et al., 1988). However, the potential productivity of a cultivar is difficult to estimate because of the many factors influencing the final yield. These factors are both genetic or internal and environmental or external, furthermore affected by their interaction. As a result of the small almond (Prunus amygdalus Batsch) fruit size, crop regularity requires the formation every year of a larger amount of flowers than in other fruit trees as well as their adequate pollination to obtain an acceptable fruit set resulting in a commercial crop level (Felipe, 2000; Godini, 2002; Kester and Griggs, 1959). As a consequence, a high fruit set is considered for a desirable trait in almond, although the adequate level of fruit set in any cultivar must be related to its flower bud density and to its flower quality (Bernad and Socias i Company, 1998; Socias i Company et al., 2004). Thus, the estimation of flower bud density of any genotype is an important step in the evaluation of its productive potential and of its value as a commercial cultivar because flower bud density is the initial basis for an adequate almond crop (Socias i Company et al., 1998). Additionally, fruit set is even more important in almond than in other fruit trees because it is not only dependent on the biological identity

Received for publication 13 July 2007. Accepted for publication 16 Sept. 2007.

This work was supported by project AGL200406674-C02-01 of the Spanish CICYT. OK gratefully acknowledges a grant from the INIA (Spanish Ministry of Science and Technology).

Technical assistance by J. Búbal, O. Frontera, and J. M. Ansón is highly appreciated.

${ }^{1}$ To whom reprint requests should be addressed; e-mail rsocias@aragon.es of each cultivar, but also on the environmental conditions, mainly at blooming time for pollination (Socias i Company and Felipe, 1992), especially for self-incompatible cultivars because the new self-compatible cultivars, and the selections studied in this report, show a lower dependence on weather conditions at bloom (Socias i Company et al., 2004).

Almond, like all other Prunus species, in summer initiates flower buds that bloom and set the next year both laterally on the previous season's growth and on spurs blooming and fruiting for several years. The almond descriptors (Gülcan, 1985) describe three basic classes of bearing habits: class 1 , most flower buds on 1-year-old shoots; class 2, most flower buds on spurs; and class 3, mixed. All of these bearing habits appear to be heritable (Gradziel et al., 2002; Kester and Asay, 1975). Spurs bear up to six lateral floral buds (Polito et al., 2002) and remain viable for 3 to 5 years (Weinbaum and Spiegel-Roy, 1985). As a result of the short spur length, fructification on spurs increases the tree productive surface and allows extending the productive period over several years (Kester and Gradziel, 1996).

As a consequence, our objective was to evaluate the variability and stability of flower bud density and number of flowers buds per spurs in almond to establish the value of spurs as a production trait and their value in the evaluation of new releases in almond breeding programs.

\section{Materials and Methods}

Nine cultivars and 48 self-compatible selections (Table 1) from the almond breeding program of the CITA of Zaragoza were included in this study. These selections are derived from five crosses among two traditional self-incompatible Spanish cultivars
(Marcona and Desmayo Largueta), a French self-incompatible one ('Ferragnès'), a Spanish self-incompatible local selection ('Bertina'), four self-compatible releases of the CITA breeding program ('Felisia', 'Guara', 'Moncayo', and 'Soleta'), and a self-compatible selection of the same program (A-10-6). They were selected because of their late blooming time, self-compatibility (Socias i Company et al., 2003), and high fruit quality (Kodad, 2006). Each selection was represented by three contiguous trees grafted on the almond $\times$ peach hybrid rootstock 'Garnem' planted in the same experimental plot managed according to the commercial recommendation for the area and formed in an open vase. They were planted in Jan. 2000 at the CITA experimental station of Zaragoza located at lat. $41^{\circ} 38^{\prime} 50^{\prime \prime} \mathrm{N}$ and long. $0^{\circ} 53^{\prime} 07^{\prime \prime} \mathrm{W}$ at $220 \mathrm{~m}$ over sea level. Seven of these genotypes were also planted in Aniñón located at lat. $41^{\circ} 26^{\prime} 45^{\prime \prime} \mathrm{N}$ and long. $1^{\circ} 42^{\prime} 15^{\prime \prime} \mathrm{W}$ at $729 \mathrm{~m}$ over sea level. The weather conditions of the two locations (temperature, rainfall, and wind speed) during the years of the study are included in Table 2 and Figures 1 and 2.

During 3 consecutive years (2003 to 2005), two trees per genotype and two branches per tree, including 1-year-old shoots and spurs, were selected at random for measurements. Although the selections have different branching habits, all branches were selected as homogeneous as possible, including the different directions around the canopy and being of the same order of branching of an approximate length of $1 \mathrm{~m}$ and placed at $\approx 1.5 \mathrm{~m}$ aboveground.

Following the criteria of Church and Williams (1983), the length of all the branchings was measured and the number of flower buds was counted on each of the four branches considering 1-year-old shoots and spurs. These measurements were done in January when flower buds were at phenological stage B (Felipe, 1977). The parameters retained for analysis were flower bud density (buds/cm), spur density (spurs/cm), and number of flower buds per spur.

All statistical analyses were performed with the SAS program (SAS Institute, 2000). The analysis of variance with the PROC GLM procedure was applied to distinguish the effect of the genotype and the year on the traits studied. The genotype and location were considered fixed effects and the year as the random effect. The mean separation was done with the least significant difference test at a probability of 0.05 . The variance components for genetic and environmental effects were calculated from the expected mean squares (Schultz, 1955) using the PROC VARCOMP procedure of SAS. Variance of a genotype mean was estimated as:

$$
\begin{aligned}
\sigma_{G}^{2}= & \sigma_{r(v)}^{2} / t+\sigma_{y v}^{2} / y+\sigma_{y r(v)}^{2} / y t \\
& \left.+\sigma_{s(t v)}^{2} / s t+\sigma_{e}^{2} / s t y\right)
\end{aligned}
$$

where $s, t, y$, and $v$ represent the number of branches, trees, years, and genotypes, 
Table 1. Characteristics of the almond cultivars and selections included in the study.

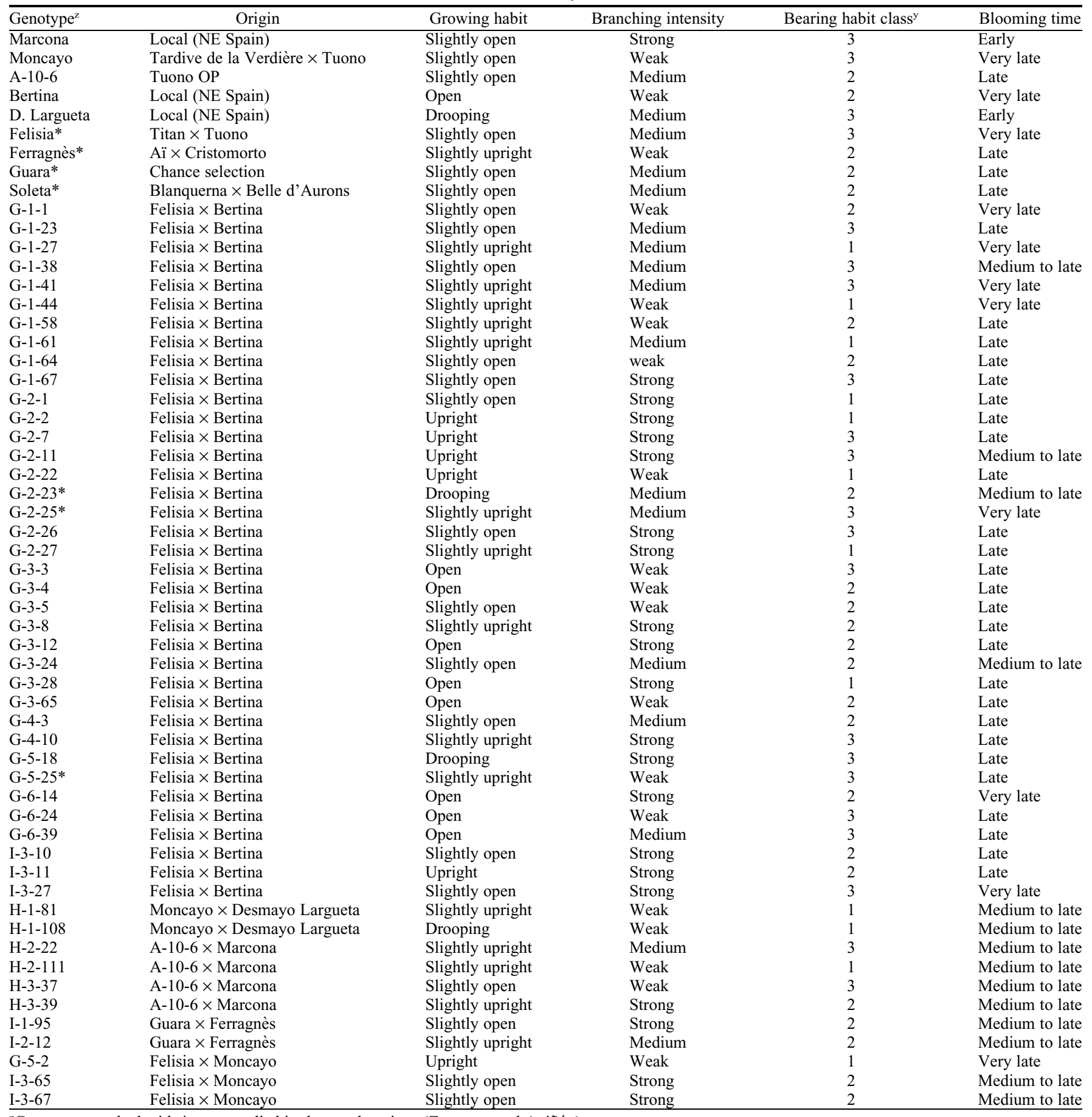

${ }^{\mathrm{z}}$ Genotypes marked with * were studied in the two locations (Zaragoza and Aniñon).

${ }^{\mathrm{y}} 1$, most flower buds on 1-year-old shoots; 2, most flower buds on spurs; 3, mixed (Gülcan, 1985).

respectively. The repeatability $(r)$ was estimated as:

$$
r=\sigma_{G}^{2} /\left(\sigma_{G}^{2}+\sigma_{e}^{2} / n_{y}\right)
$$

where $\sigma_{G}^{2}$ is the variance between genotype, $\sigma_{e}^{2}$ is the residual variance, and $n_{y}$ the number of years.

The correlation coefficients between the variables studied and between the years were calculated to determine the consistency of the year-to-year data. The Pearson correlation coefficients were calculated with the PROC CORR procedure.

\section{Results}

Genotypic and environmental variability. All parameters measured showed a large variability as shown in Table 3. Values for flower bud density ranged from 0.03 to 1.52 in 2003, from 0.08 to 0.97 in 2004 , and from 0.33 to 1.29 in 2005 . Spur density ranged from 0.01 to $1.27 \mathrm{spurs} / \mathrm{cm}$ in 2003 , from 0.02 to 0.99 in 2004, and from 0.12 to 1.20 in 2005 . The number of flower buds per spur ranged from 0 to 6.67 in 2003 , from 0.87 to 4.49 in 2004, and from 2.54 to 9.92 in 2005 . For flower bud density and the number of buds per spur, the lowest values were observed in 2004 and the highest in 2005, but for spur density, the values increased from year to year. Selections showing a high flower bud density such as I-2-12 also showed a high number of spurs.

To test the relationship between the different traits in each year, their phenotypic correlations were calculated (analysis not shown). Flower bud density was positively correlated with spur density $\left(r^{2}=0.4,0.57\right.$, and 0.59 for the 3 years) as well as with the number of flower buds per spur $\left(r^{2}=0.57\right.$, 
Table 2. Climatic characteristics (temperature, rainfall, and wind) during bloom (March), fruit development (May to July), and bud differentiation (July to August) in Zaragoza.

\begin{tabular}{|c|c|c|c|c|c|c|}
\hline \multirow[b]{2}{*}{ Year } & & \multicolumn{5}{|c|}{ Month } \\
\hline & & March & May & June & July & August \\
\hline \multicolumn{7}{|c|}{ Temperature $\left({ }^{\circ} \mathrm{C}\right)$} \\
\hline \multirow[t]{5}{*}{2002} & Maximum & 18.4 & 22.6 & 29.6 & 30.3 & 19 \\
\hline & Mean & 12 & 16.4 & 22 & 23.1 & 16.2 \\
\hline & Minimum & 5.6 & 10.3 & 14.4 & 15.9 & 22.6 \\
\hline & Absolute minimum & -2 & 6.5 & 9 & 12.2 & 12.5 \\
\hline & Absolute maximum & 27.5 & 31 & 36 & 37.5 & 36.2 \\
\hline \multirow[t]{5}{*}{2003} & Maximum & 18.4 & 24.6 & 33.6 & 33.1 & 34.3 \\
\hline & Mean & 11.4 & 17.8 & 25.6 & 17.8 & 25.9 \\
\hline & Minimum & 4.3 & 11 & 17.7 & 25.4 & 17.6 \\
\hline & Absolute minimum & -2.5 & 6.9 & 14.7 & 14.3 & 13.5 \\
\hline & Absolute maximum & 22 & 32.5 & 39 & 38.2 & 38 \\
\hline \multirow[t]{5}{*}{2004} & Maximum & 14.4 & 22.7 & 31.1 & 32.5 & 31.6 \\
\hline & Mean & 8.3 & 16.1 & 23.2 & 23.3 & 24.1 \\
\hline & Minimum & 2.6 & 8.7 & 14.8 & 16.1 & 16.4 \\
\hline & Absolute minimum & -4.8 & 4.2 & 9 & 11.7 & 12 \\
\hline & Absolute maximum & 23.5 & 29.7 & 38.7 & 36.3 & 35.5 \\
\hline \multicolumn{7}{|c|}{ Rainfall (mm) } \\
\hline 2002 & & 49.9 & 71 & 52.2 & 43.2 & 10.2 \\
\hline 2003 & & 31.9 & 78.3 & 21.9 & 0.2 & 8.5 \\
\hline 2004 & & 66.4 & 44.6 & 10 & 28.4 & 14.3 \\
\hline \multicolumn{7}{|c|}{ Average daily mean wind speed $\left(\mathrm{m} \cdot \mathrm{s}^{-1}\right)$} \\
\hline 2002 & & 2.3 & 2.3 & 2.1 & 2.4 & 1.8 \\
\hline 2003 & & 2.2 & 2.6 & 2.5 & 2.5 & 2 \\
\hline 2004 & & 2.5 & 2.8 & 2.5 & 2.3 & 1.7 \\
\hline
\end{tabular}

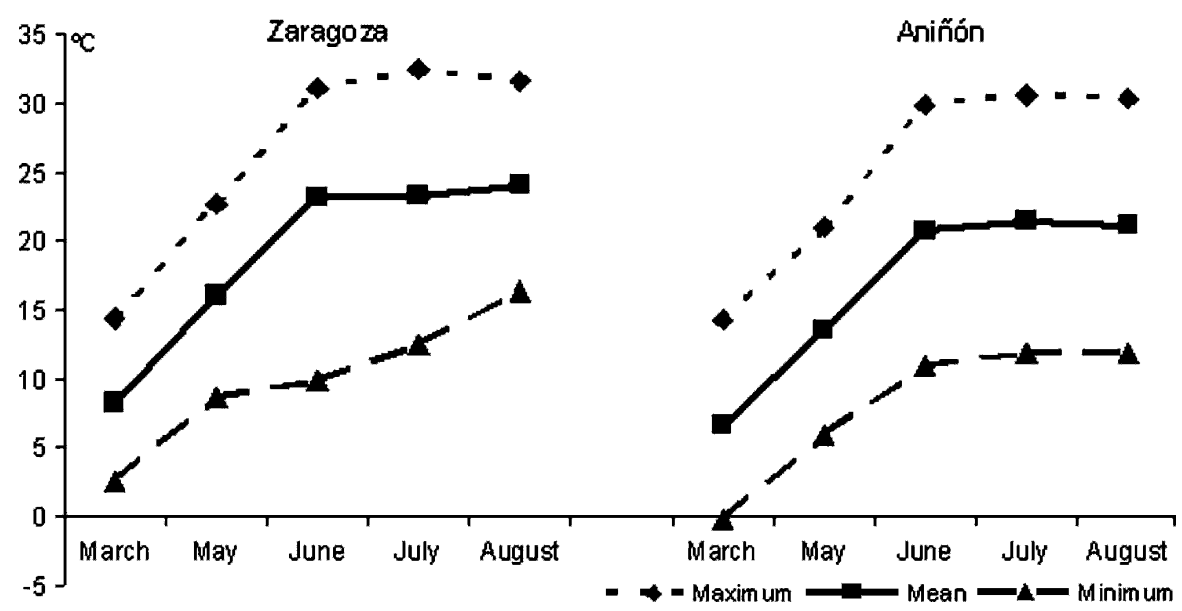

Fig. 1. Mean temperatures during the vegetative period at the two locations where flower bud density was evaluated.

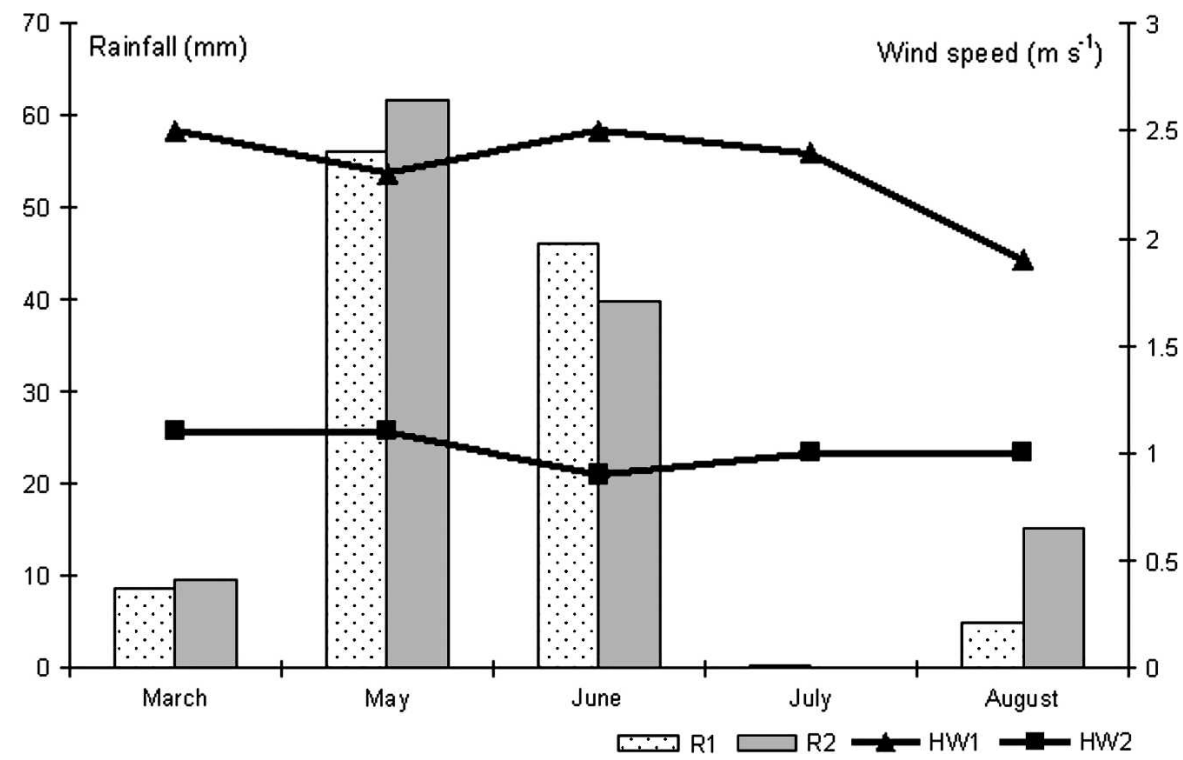

Fig. 2. Rainfall and wind speed at the two locations where flower bud density was evaluated (R1: Rainfall in Zaragoza; R2: Rainfall in Aniñón; HW1: Wind speed in Zaragoza; HW2: Wind speed in Aniñón).
0.67, and 0.31). However, no significant correlations were found between spur density and the number of flower buds per spur.

As expected, the analysis of variance showed significant differences for all measured traits between genotypes and years. The interaction genotype $\times$ year was also significant (Table 4). Variation between trees within cultivars [tree (genotype)] was nonsignificant for all traits studied. However, the year $\times$ tree (genotype) and genotype $\times$ year effects were significant. Because variances resulting from the year effect were high for all traits, the year variance is the main contributor to total variance. Genotypic variance was only the third factor contributing to the total variance for flower bud density and spur density.

The statistical analysis of data from seven genotypes in two locations showed that the effect of the location and the interaction genotype $\times$ location were significant for spur density and the number of flower buds per spur, but not for flower bud density (Table 5). Variation between trees within genotype [tree (genotype $\times$ location)] was significant for all traits studied, confirming tree variability and the need to consider a group of trees of each genotype. For spur density, the values obtained in Aniñon were lower than those observed in Zaragoza, although for the number of flower buds per spur, the opposite took place. These results indicate that these genotypes maintain the same bud flower potential over different environments.

Family variability. As a result of the high number of selections from the cross 'Felisia' $x$ 'Bertina' (37 selections), analysis of variance was applied only to this progeny, showing also a large variability for these three traits as confirmed by the significant differences found among the siblings and the years (Table 6). The genotype $\times$ year effect was significant, showing the differential response of each genotype to the variation of conditions from year to year independently of the same genetic origin. As a consequence, variability is not only inherited from the parents, but it is also the result of each genotype. For flower bud density, the year effect was important in some genotypes (G1-1, G-1-64, G-1-58, G-3-8, G-5-25, and G-6-14), but in others, such as G-1-23 and G$2-11$, the values were stable throughout the 3 years. Spur density generally increased with time. The number of buds per spur was very variable throughout the years in some genotypes (G-2-26, G-3-65, G-6-39, and I-3-27), but in others (G-2-11, G-3-5, and G-5-25) was more stable. Repeatability estimates from 3 years of data showed that the lowest values were for flower bud density and the number of flowers buds per spur and intermediate for spur density (Table 6).

\section{Discussion}

Variability and repeatability. The variability observed agrees with previous results in other almond cultivars and selections (Bernad and Socias i Company, 1998; Socias i Company, 1988) as well as in other species 
Table 3. Flower bud density, spur density and number of flower buds per spur in the genotypes studied in Zaragoza.

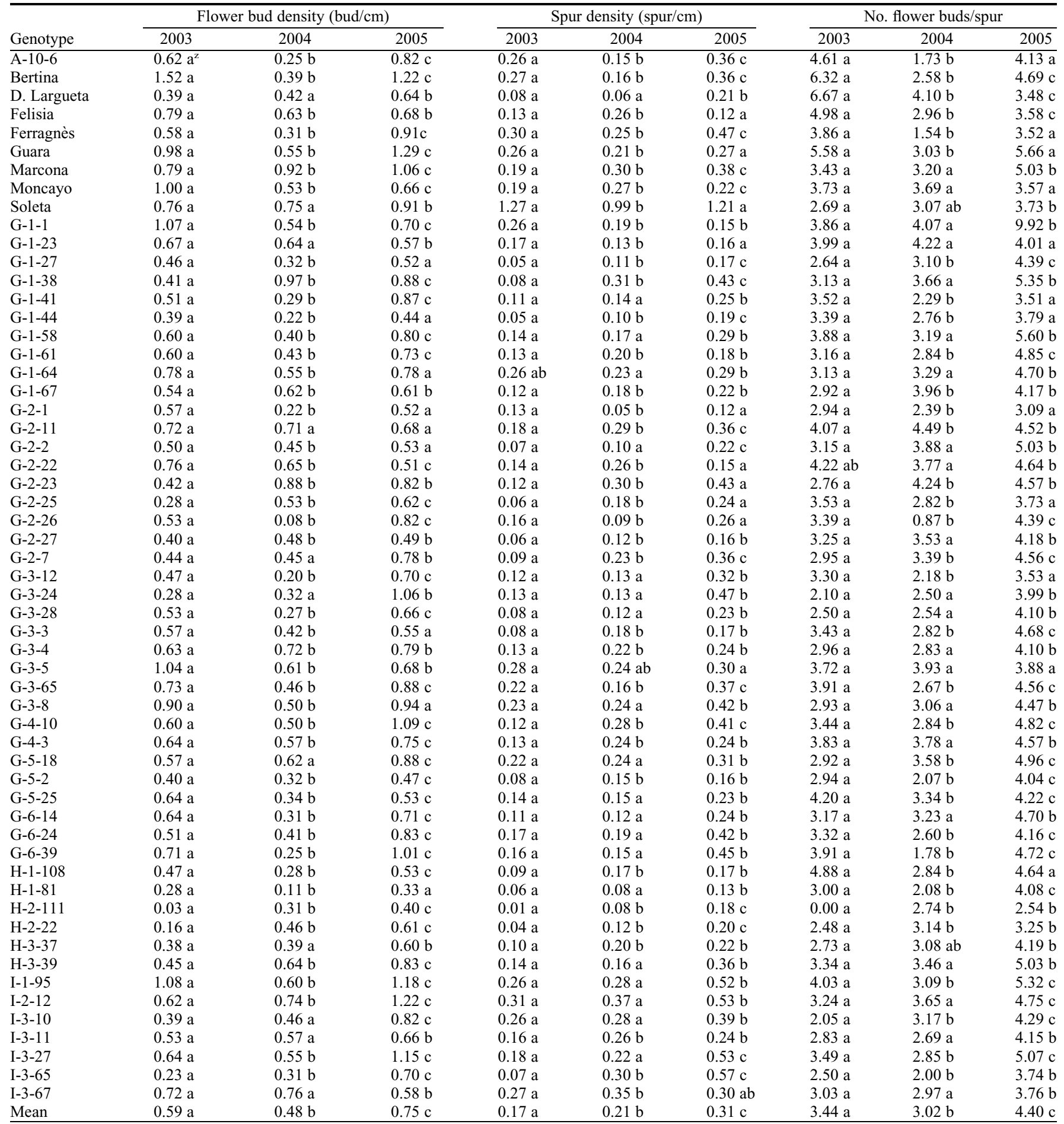

${ }^{\mathrm{z}}$ Means of each component of every genotype followed by different letters in different years are significantly different at $P=0.01$.

such as peach (Okie and Werner, 1996; Werner et al., 1988) and apricot (Alburquerque et al., 2004). However, the variance resulting from the year and the interaction genotype $x$ year exceeds that two and three times as a result of the genotype effect (Table 4), variability probably related to the low heritability estimated for flower bud density between 0.26 and 0.30 (Sarvisé and Socias i Company, 2005), indicating that the genetic factors controlling flower bud density are highly conditioned by the environment.
In almond, like in other species (Raseira and Moore, 1986), flower bud density depends on the floral initiation taking place during the previous year (Lamp et al., 2001) from the beginning to the end of summer depending on the cultivar and the environmental conditions such as high temperature and moisture stress (Jacoboni and Pinnola, 1994). Any disturbance during this period may shift or damage the normal development of flower initiation and differentiation (Lamp et al., 2001). Water also plays an important role in bud development, mainly during summer, and any water stress may impair this process leading to an inhibition of flower formation (Kester and Gradziel, 1996) and, thus, in a reduction of the number of flower buds (Goldhamer and Viveros, 2000). This reduction may also be the result of poor nutrition of the plant as a result of the lack of carbohydrate accumulation (Kozlowski et al., 1991) or a deficient nutrient distribution within the plant because of disequilibrium between vegetative growth and flower 
Table 4. Analysis of variance of flower bud density, spur density, and number of flower buds per spur in Zaragoza for the ensemble of nine cultivars and 48 selections of almond.

\begin{tabular}{|c|c|c|c|c|c|c|c|}
\hline \multirow[b]{2}{*}{ Source of variation } & \multirow[b]{2}{*}{ df } & \multicolumn{2}{|c|}{ Flower bud density } & \multicolumn{2}{|c|}{ Spur density } & \multicolumn{2}{|c|}{ No. flower buds/spur } \\
\hline & & $\mathrm{MS}^{\mathrm{z}}$ & $\mathrm{VC}$ & MS & $\overline{\mathrm{VC}}$ & MS & $\mathrm{VC}$ \\
\hline Genotype & 56 & $0.34 * * *$ & .0118 & $0.25 * * *$ & 0.0028 & $4.65^{* * *}$ & 0.0156 \\
\hline Year & 2 & $38 * * *$ & 52 & $1.15^{* * *}$ & 0.0049 & $113.8 * * *$ & 0.4879 \\
\hline Genot & 112 & $0.13^{* * *}$ & 0.025 & $0.02 * * *$ & 0.003 & $2.62 * *$ & 0.2558 \\
\hline renotype & 57 & $0.03 \mathrm{NS}$ & 0.001 & $0.01 \mathrm{NS}$ & 0.0013 & $1.46 \mathrm{NS}$ & 0.0253 \\
\hline Year $\times$ tree $($ geno & 114 & $0.047 * *$ & 0.0027 & $0.10^{* *}$ & 0.0022 & $1.59^{*}$ & 0.094 \\
\hline & 114 & & & $0.08 \mathrm{NS}$ & 0.0008 & $1.92 \mathrm{~N}$ & 0.0267 \\
\hline Residual & 228 & 0.028 & 0.0291 & 0.03 & 0.008 & 5.39 & 0.0156 \\
\hline
\end{tabular}

${ }^{\mathrm{z}} \mathrm{MS}=$ mean square; $\mathrm{VC}=$ variance component.

Ns, **, **** Nonsignificant or significant of the mean squares at $P<0.01,0.001$, respectively.

Table 5. Analysis of variance for flower bud density, spur density, and number of flower buds per spur in seven genotypes at two different locations.

\begin{tabular}{lrccc}
\hline & & \multicolumn{3}{c}{ Mean square } \\
\cline { 4 - 5 } Source of variation & df & Flower bud density & Spur density & No. flower buds/spur \\
\hline Genotype & 1 & $0.09^{*}$ & $0.17^{* * *}$ & $1.62^{* *}$ \\
Location & 6 & $0.002 \mathrm{NS}$ & $0.22^{* * *}$ & $6.30^{* * *}$ \\
Genotype $\times$ location & 6 & $0.11 \mathrm{NS}$ & $0.18^{* *}$ & $1.52^{*}$ \\
Tree $($ genotype $\times$ location) & 14 & $0.09^{* *}$ & $0.06^{* *}$ & $0.77^{*}$ \\
Residual & 28 & 0.06 & 0.0205 & 0.42 \\
\hline Ns, ${ }^{* *}{ }^{* *},{ }^{* * *}$ Nonsignificant or significant of the mean squares at $P<0.05,0.01,0.001$, respectively.
\end{tabular}

Table 6. Analysis of variance for flower bud density, spur density, and number of flower buds per spur in the family 'Felisia' $\times$ 'Bertina' (37 genotypes, 3 years).

\begin{tabular}{lrccc}
\hline & & \multicolumn{3}{c}{ Mean square } \\
\cline { 3 - 5 } Source of variation & df & Flower bud density & Spur density & No. flower buds/spur \\
\hline Genotype & 36 & $0.16^{* * *}$ & $0.04^{* * *}$ & $3.74^{* * *}$ \\
Year & 2 & $2.61^{* * *}$ & $0.81^{* * *}$ & $89.4^{* * *}$ \\
Genotype $\times$ year & 72 & $0.11^{* * *}$ & $0.017^{* * *}$ & $1.98^{* * *}$ \\
Tree $\times$ genotype & 37 & $0.02 \mathrm{NS}$ & $0.005 \mathrm{NS}$ & $1.007 \mathrm{NS}$ \\
Year $\times$ tree (genotype) & 74 & $0.14^{* *}$ & $0.01^{* * *}$ & $1.38^{* * *}$ \\
Branches (tree $\times$ genotype) & 74 & $0.03^{*}$ & $0.009^{*}$ & $0.92 \mathrm{NS}$ \\
Residual & 221 & 0.024 & 0.006 & 0.99 \\
Repeatability & & 0.42 & 0.52 & 0.47
\end{tabular}

Ns, ${ }^{*}, * *, * * *$ Nonsignificant or significant of the mean squares at $P<0.1,0.01,0.001$, respectively.

Table 7. Means and year to year correlation $(n=57)$ of the studied traits.

\begin{tabular}{lccccccc}
\hline & \multicolumn{3}{c}{ Mean value } & & \multicolumn{3}{c}{ Correlation coefficient } \\
\cline { 2 - 4 } \cline { 6 - 8 } Trait & 2003 & 2004 & 2005 & & 2003 vs. 2004 & 2003 vs. 2005 & 2004 vs. 2005 \\
\hline Flower bud density (buds/cm) & 0.59 & 0.48 & 0.75 & & $0.28 \mathrm{NS}^{\mathrm{z}}$ & $0.47 \mathrm{NS}$ & $0.30 \mathrm{NS}$ \\
No. spurs/cm & 0.17 & 0.21 & 0.31 & & $0.86^{* * *}$ & $0.78^{* * *}$ & $0.79^{* * *}$ \\
No. flower buds/spur & 3.44 & 3.02 & 4.40 & & $0.01 \mathrm{NS}$ & $0.22 \mathrm{NS}$ & $0.22 \mathrm{NS}$ \\
\hline
\end{tabular}

Ns, ${ }^{* *},{ }^{* * *}$ Nonsignificant or significant of the mean squares at $P<0.01,0.001$, respectively.

differentiation (Goldhamer and Viveros, 2000).

As mentioned, the values of 2004 were the lowest of the 3 years for all traits. The differences between years may be the result of the climatic conditions of the previous growing season. The summer of 2003 was extremely hot and dry (Table 2) with temperatures higher than in 2002 and 2004. This fact could have a negative effect on flower initiation, resulting in a lower bud density in 2004 as suggested by Werner et al. (1988) to explain the year-to-year differences of flower bud density in 25 peach and nectarine cultivars. Although the growing conditions in 2002 were better than in 2004 , the values observed in 2003 were lower than those in 2005 , probably because of the low age of the trees (fourth leaf in 2003), because they had not reached a mature stage. showing the importance to increase the number of trees to examine more precisely the genotype stability over different environments.

The high repeatability (Table 6) and yearto-year correlation (Table 7) obtained for spur density suggest that the effect of the genetic factors controlling spur density exceeds that of the environment factors even if the location and year effects are statistically significant. On the other hand, the number of flower buds per spur was highly affected by the environmental conditions such as high temperature, moisture stress, and wind speed.

Growing habits in almond appear to be heritable (Gradziel et al., 2002; Kester and Asay, 1975), but no work has been undertaken to estimate their heritability. Repeatability gives a good indication of broad-sense heritability (Falconer, 1960) and our results show a high repeatability for spur density and low for flower bud density and the number of flower buds per spur (Table 6). This suggests that broad-sense heritability for spur density is higher than for flower bud density and the number of flower buds per spur. The low repeatability (Table 6) and year-to-year correlation (Table 7) of the flower bud density confirm that climatic conditions strongly affect the flower bud potential expression in almond (Bernad and Socias i Company, 1998). The genotypic and year-to-year variation in flower bud density, spur density, and number of flowers per spurs observed in the family 'Felisia' $x$ 'Bertina' suggest that all these traits are under polygenic and environmental control (high temperature and water stress) as proposed by Sarvisé and Socias i Company (2005) for flower bud density.

It has been reported that some almond cultivars are prone to alternance if not well managed, including 'Marcona', 'Cristomorto' (Felipe, 2000), 'Ferraduel' (Grasselly and Crossa-Raynaud, 1980), 'Price', and 'Sonora' (Kester and Gradziel, 1996). During the 3 years, it was not easy to follow the possibilities of alternance in the cultivars and selections studied. However, selections that showed a clear variation for flower bud density among the 3 years could be eliminated and a positive selection must be carried out at the individual level with preference for those genotypes with high flower bud and spur density without alternating values.

Cultivar evaluation. Not much attention has been devoted to understanding the role of spurs on flower bud density, productivity, and regular production in almond (Kester and Gradziel, 1996; Polito et al., 2002). Flower bud density shows a high phenotypic correlation with spur density and to a lesser degree with the number of flower buds per spur (Kodad and Socias i Company, 2006). This may allow indirect selection for high flower bud density by increasing spur density. A high spur density may not only increase the productive surface area, but also extend the productivity over several years as reported by Kester and Gradziel (1996) in almond and Alburquerque et al. (2003) in apricot. In 
addition, the influence of the morphological traits of the fruiting branches on flower characteristics (Bernad and Socias i Company, 1998; Kodad and Socias i Company, 2006) indicate that plant morphology, including vigor, growing habit, and branching pattern, must be taken into account when evaluating the productive parameters. Production evaluation in almond is based on an ensemble of parameters, including the number of fruits per tree, kernel weight, and percentage of defects (Godini, 2002; Kester and Gradziel, 1996). These parameters depend in turn on other traits such as bloom density and are under environmental and genetic control (Kester, 1989).

Californian cultivars such as Nonpareil show a lower flower bud density than traditional Spanish cultivars such as Marcona and new releases from the CITA breeding program such as 'Guara' (Socias i Company, 1988). A high flower bud density has been shown to increase the possibility to endure a late frost during bloom (Kodad and Socias i Company, 2005) because the presence of a high number of flowers increases the possibility of survival of some flowers after a frost, thus allowing an acceptable crop. Frost risks are lower in California than in Spain, thus leading to the prevalence of cultivars with low or medium flower bud density, probably to reduce the problems related to flower quality (Socias i Company and Felipe, 1994), whereas in Spain, where frost risks are important (Felipe, 1988), a high flower bud density has been a positive trait for cultivar evaluation to ensure a crop, as it happened with the new cultivar 'Soleta', which shows the highest value of flower bud density. The same hypothesis has been put forward to explain the high flower bud density of some peach cultivars from the United States, Canada (Okie and Werner, 1996; Werner et al., 1988), and Hungary (Szabó et al., 1998).

\section{Conclusion}

For long-lasting production, it is advisable to select for a high density of spurs independently of the number of flowers per spur. In addition, in conditions in which there is risk of frosts, a high number of flowers may compensate the frost damage and allow an acceptable crop level. The absence of any significant correlation between the different years for flower bud density and the low values of the repeatability coefficient show that the values obtained in the first evaluation year are not enough to predict the values that can be obtained in the following years, indicating the need to evaluate this character in several years to determine the real flower productivity of each promising genotype, even at the expense of a considerable experimental effort.

\section{Literature Cited}

Alburquerque, N., L. Burgos, and J. Egea. 2003. Apricot flower bud development and abscission related to chilling, irrigation and type of shoots. Scientia Hort. 98:265-276.

Alburquerque, N., L. Burgos, and J. Egea. 2004. Influence of flower bud density, flower bud drop and fruit set on apricot productivity. Scientia Hort. 102:397-406.

Bernad, D. and R. Socias i Company. 1998. Bud density and shoot morphology of some selfcompatible almond selections. Acta Hort. 470:273-279.

Church, R.M. and R.R. Williams. 1983. Comparison of flower number and pollen production of several dessert apple and ornamental Malus cultivars. J. Hort. Sci. 58:327-336.

Falconer, D.S. 1960. Introduction to quantitative genetics. Ronald Press Co., New York, NY.

Felipe, A.J. 1977. Almendro. Estados fenológicos. Inf. Técn. Econ. Agrar. 27:8-9.

Felipe, A.J. 1988. Observaciones sobre comportamiento frente a heladas tardías en almendro. Rap. EUR 11557:145-148.

Felipe, A.J. 2000. El almendro: El material vegetal. Integrum, Lérida.

Godini, A. 2002. Almond fruitfulness and role of self-fertility. Acta Hort. 591:191-204.

Goldhamer, D.A. and M. Viveros. 2000. Effects of preharvest irrigation cut-off duration and postharvest water deprivation on almond tree performance. Irrig. Sci. 19:125-131.

Gradziel, T.M., D.E. Kester, and P. MartínezGómez. 2002. A development based classification for branch architecture in almond. J. Amer. Pomol. Soc. 56:106-112.

Grasselly, C. and P. Crossa-Raynaud. 1980. L'amandier. G.P. Maisonneve et Larouse, Paris, France.

Gülcan, R. 1985. Almond descriptors (revised). IBPGR, Rome, Italy.

Jacoboni, A. and I.A. Pinnola. 1994. Climatological relationships of almond. Acta Hort. 373:167176.

Kester, D.E. 1989. An almond development model for analyzing yield. HortScience 24:133.

Kester, D.E. and R.N. Asay. 1975. Almonds, p. 387-419. In: Janick, J. and J.N. Moore (eds.). Advances in fruit breeding. Purdue Univ. Press, West Lafayette, IN.

Kester, D.E. and T.M. Gradziel. 1996. Almonds, p. 1-97. In: Janick, J. and J.N. Moore (eds.). Fruit breeding. Vol. III. John Wiley \& Sons, New York, NY.

Kester, D.E. and W.H. Griggs. 1959. Fruit setting in the almond: The effect of cross-pollinating various percentages of flowers. Proc. Amer. Soc. Hort. Sci. 74:214-219.

Kodad, O. 2006. Criterios de selección y de evaluación de nuevas obtenciones autocompatibles en un programa de mejora genética del almendro. Univ. Lérida. PhD Thesis.

Kodad, O. and R. Socias i Company. 2005. Daños diferenciales por heladas en flores y frutos y criterios de selección para la tolerancia a heladas en el almendro. Inf. Técn. Econ. Agrar. 101:349-365

Kodad, O. and R. Socias i Company. 2006. Influence of genotype, year and type of fruiting branches on the productive behaviour of almond. Scientia Hort. 109:297-302.

Kozlowski, T.T., P.J. Kramer, and S.G. Pallardy. 1991. The physiological ecology of woody plants. Stanford Univ., Stanford, CA.

Lamp, B.M., J.H. Connell, R.A. Duncan, M. Viveros, and V.S. Polito. 2001. Almond flower development: Floral initiation and organogenesis. J. Amer. Soc. Hort. Sci. 126:689-696.

Okie, W.R. and D.J. Werner. 1996. Genetic influence on flower bud density in peach and nectarine exceeds that of environment. HortScience 31:1010-1012.

Polito, V.S., K. Pinney, R. Heerema, and S.A. Weinbaum. 2002. Flower differentiation and spur leaf area in almond. J. Hort. Sci. Biotechnol. 77:474-478.

Raseira, M.C.B. and J.N. Moore. 1986. Comparison of flower bud initiation in peach cultivars in northern and southern hemispheres. HortScience 21:1367-1368.

Sarvisé, R. and R. Socias i Company. 2005. Variability and heritability of bud density and branching habit in almond. Acta Hort. 663: 401-404.

SAS Institute. 2000. SAS/STAT user's guide. SAS Institute, Cary, NC.

Schultz, E.F., Jr. 1955. Rules of thumb for determining expectations of mean squares in analysis of variance. Biometrics 11:123 125.

Socias i Company, R. 1988. La densité florale comme critère vatiétal chez l'amandier. Rap. EUR 11557:119-122.

Socias i Company, R., J.M. Alonso, and J. Gómez Aparisi. 2004. Fruit set and productivity in almond as related to self-compatibility, flower morphology and bud density. J. Hort. Sci. Biotechnol. 79:754-758.

Socias i Company, R. and A.J. Felipe. 1992. Selfcompatibility and autogamy in 'Guara' almond. J. Hort. Sci. 67:313-317.

Socias i Company, R. and A.J. Felipe. 1994. Flower quality and fruit quality in almond: Conflicting objectives? p. 245-248. In: Schmidt, H. and M. Kellerhals (eds.). Progress in temperate fruit breeding. Kluwer Academic Publ., Dordrecht, The Netherlands.

Socias i Company, R., A.J. Felipe, and J. Gómez Aparisi. 2003. Almond bloom in a changing climate. J. Amer. Pomol. Soc. 57:89-92.

Socias i Company, R., A.J. Felipe, J. Gómez Aparisi, J.E. García, and F. Dicenta. 1998. The ideotype concept in almond. Acta Hort. 470:51-56.

Szabó, Z., J. Nyéki, I. Szél, A. Pedryc, and A. Szalay. 1998. Low temperature injury in peach and nectarine cultivars. Acta Hort. 465:339404.

Weinbaum, S.A. and P. Spiegel-Roy. 1985. Role of natural self-pollination in self-fruitfulness in almond. Scientia Hort. 27:295-302.

Werner, D.J., B.D. Mowrey, and J.X. Chaparro. 1988. Variability in flower bud number among peach and nectarine clones. HortScience 23: $578-580$. 